\title{
Graphical Method for the Determination of the Complex NMR Shift and Equilibrium Constant for a Hetero-Association Accompanying Self- Associations
}

\author{
Chi-Chyuang Lin, Cheng-Yu Fang, Dah-Yu Kao, and \\ Jenn-Shing Chen*
}

Received July 25, 1996; revised July 10, 1997

\begin{abstract}
We describe a novel graphical method which, in conjunction with the previously proposed graphical determination of monomer shift, dimer shift, and dimerization constant for self-association, allows us to determine the complex shift and equilibrium constant for a hetero-association, $\mathrm{A}+\mathrm{B} \rightleftharpoons \mathrm{AB}$, accompanying self-associations, $A+A \rightleftharpoons A_{2}$, and $B+B \rightleftharpoons B_{2}$. The merit of the new method includes the removal of the restrictions imposed on the conventional Benesi-Hildebrand (B-H) plot: (1) that the concentration of one component must be much less than that of the other; (2) that there be no accompanying self-association. The simultaneous equilibrium of the self-association of 2-pyrrolidone (A) and that of 4-methyl- $\alpha$-pyrrolidone (B) and the hetero-association between $\mathrm{A}$ and $\mathrm{B}$ in acetonitrile- $\mathrm{d}_{3}$ at $25^{\circ} \mathrm{C}$ is studied. The inappropriateness of the $\mathrm{B}-\mathrm{H}$ plot in dealing with this case is also pointed out.
\end{abstract}

KEY WORDS: Self-association; hetero-association; NMR shift; graphical method.

\section{INTRODUCTION}

Molecular association arising from hydrogen bonding or electron donorelectron acceptor charge transfer is of importance in chemistry and biochemistry, and has long been of interest to chemists. ${ }^{(1-4)}$ A variety of experimental as well as theoretical means have been employed to study this phenomenon. ${ }^{(5-7)}$ The traditional approach to derive spectroscopic parameters and the

Department of Applied Chemistry, National Chiao Tung University, Hsin Chu, 30050, Taiwan. 
equilibrium constant for a hetero-association from experimental data (UV or NMR) was pioneered by Benesi and Hildebrand $(\mathrm{B}-\mathrm{H}) \cdot{ }^{\left({ }^{(8)}\right.}$ However, the B-H plot or its modifications, Scatchard ${ }^{(9)}$ and Scott ${ }^{(10)}$ plots, are subject to the limitation that the concentration of one component must be much less than that of the other. The solutions prepared under this restriction give unwanted results: (1) monitored signal is too weak to be observed, (2) an extended association such as $\mathrm{AB}_{2}, \mathrm{AB}_{3}$, etc., takes place, (3) the solution is thermodynamically nonideal so that activity, instead of concentration, should be used in the equilibrium constant expression. Another restriction is also implied, although not explicitly expressed, that the self-association of species is not allowed. This restriction, as a matter of fact, seriously limits the scope of the application of B-H method, since in many cases, self-association of the constituent species is inevitable. An outstanding example ${ }^{(11)}$ is the basepairing of adenine-thymine, gutamine-cytosine, in which self-association can by no means be ignored.

In the previous study, ${ }^{(12)}$ in conjunction with a graphical method for determination of monomer shift, dimer shift, and dimerization constant of self-association, ${ }^{(13-15)}$ we have proposed an algorithm to deal with a system which involves simultaneous equilibria $\mathrm{A}+\mathrm{B} \rightleftharpoons \mathrm{AB}$, and $\mathrm{A}+\mathrm{A} \rightleftharpoons \mathrm{A}_{2}$, without the restrictions imposed on the $\mathrm{B}-\mathrm{H}$ method. Extension of this treatment to include the self-association $B+B \rightleftharpoons B_{2}$ is presented here.

\section{THEORY}

Consider a system containing species A and B in a solvent. A and B undergo hetero-association

$$
\mathrm{A}+\mathrm{B} \rightleftharpoons \mathrm{AB} ; \quad K_{\mathrm{C}}=\frac{[\mathrm{AB}]}{[\mathrm{A}][\mathrm{B}]}
$$

and accompanying self-associations

$$
\begin{array}{ll}
\mathrm{A}+\mathrm{A} \rightleftharpoons \mathrm{A}_{2} ; & K_{\mathrm{A}}=\frac{\left[\mathrm{A}_{2}\right]}{[\mathrm{A}]^{2}} \\
\mathrm{~B}+\mathrm{B} \rightleftharpoons \mathrm{B}_{2} ; & K_{\mathrm{B}}=\frac{\left[\mathrm{B}_{2}\right]}{[\mathrm{B}]^{2}}
\end{array}
$$

Here $[A],\left[A_{2}\right]$ are the equilibrium concentrations of monomer. $A$, and dimer $A_{2}$, respectively; their counterparts for $B$ are $[B]$ and $\left[B_{2}\right]$. $[A B]$ is the equilibrium concentration of the complex AB. $K_{\mathrm{A}}$ and $K_{\mathrm{B}}$ are respectively, 
the dimerization constants of $\mathrm{A}$, and B. $K_{\mathrm{C}}$ is the equilibrium constant for hetero-association. Consideration of mass balance results in

$$
\begin{aligned}
& {[\mathrm{A}]_{\mathrm{o}}=[\mathrm{A}]+[\mathrm{AB}]+2\left[\mathrm{~A}_{2}\right]=[\mathrm{A}]+K_{\mathrm{C}}[\mathrm{A}][\mathrm{B}]+2 K_{\mathrm{A}}[\mathrm{A}]^{2}} \\
& {[\mathrm{~B}]_{\mathrm{o}}=[\mathrm{B}]+[\mathrm{AB}]+2\left[\mathrm{~B}_{2}\right]=[\mathrm{B}]+K_{\mathrm{C}}[\mathrm{A}][\mathrm{B}]+2 K_{\mathrm{B}}[\mathrm{B}]^{2}}
\end{aligned}
$$

where $[A]_{0}$ and $[B]_{0}$ are, respectively, the initial concentrations of $A$ and $B$. The last equalities in Eqs. $(4,5)$ result from the use of equilibrium constant expressions $(1-3)$. The ratios $[A B] /[A]_{0}$ and $[A B] /[B]_{0}$ can be expressed as

$$
\begin{aligned}
& \frac{[\mathrm{AB}]}{[\mathrm{A}]_{\mathrm{o}}}=\frac{K_{\mathrm{C}}[\mathrm{B}]}{1+K_{\mathrm{C}}[\mathrm{B}]+2 K_{\mathrm{A}}[\mathrm{A}]} \\
& \frac{[\mathrm{AB}]}{[\mathrm{B}]_{\mathrm{o}}}=\frac{K_{\mathrm{C}}[\mathrm{A}]}{1+K_{\mathrm{C}}[\mathrm{A}]+2 K_{\mathrm{B}}[\mathrm{B}]}
\end{aligned}
$$

In NMR measurements, the observed chemical shift for a nucleus in molecule $\mathrm{A}$, which involves a rapid exchange between the states of monomer $\mathrm{A}$, dimer $\mathrm{A}_{2}$, and complex $\mathrm{AB}$, is the weighted average of their shifts, with the respective mole fractions as weight factors. According to Gutowsky and Saika, ${ }^{(16)}$ the observed shift $\Delta \nu_{\text {obs }}^{\mathrm{A}}$ is given by

$$
\Delta v_{\mathrm{obs}}^{\mathrm{A}}=\frac{[\mathrm{A}]}{[\mathrm{A}]_{\mathrm{o}}} \Delta v_{\mathrm{m}}^{\mathrm{A}}+\frac{2\left[\mathrm{~A}_{2}\right]}{[\mathrm{A}]_{\mathrm{o}}} \Delta v_{\mathrm{d}}^{\mathrm{A}}+\frac{[\mathrm{AB}]}{[\mathrm{A}]_{\mathrm{o}}} \Delta v_{\mathrm{c}}^{\mathrm{A}}
$$

where $\Delta v_{\mathrm{m}}^{\mathrm{A}}, \Delta v_{\mathrm{d}}^{\mathrm{A}}$, and $\Delta v_{\mathrm{c}}^{\mathrm{A}}$ are, respectively, the chemical shifts of the monitored nucleus in molecule $A$, in the states of monomer, dimer, and complex. Similar result can be applied to the monitored nucleus in molecule B

$$
\Delta \nu_{\mathrm{obs}}^{\mathrm{B}}=\frac{[\mathrm{B}]}{[\mathrm{B}]_{\mathrm{o}}} \Delta \nu_{\mathrm{m}}^{\mathrm{B}}+\frac{2\left[\mathrm{~B}_{2}\right]}{[\mathrm{B}]_{\mathrm{o}}} \Delta \nu_{\mathrm{d}}^{\mathrm{B}}+\frac{[\mathrm{AB}]}{[\mathrm{B}]_{\mathrm{o}}} \Delta \nu_{\mathrm{c}}^{\mathrm{B}}
$$

where $\Delta \nu_{\mathrm{m}}^{\mathrm{B}}, \Delta \nu_{\mathrm{d}}^{\mathrm{B}}$, and $\Delta \nu_{\mathrm{c}}^{\mathrm{B}}$ are, respectively, the chemical shifts of the monitored nucleus in molecule $\mathrm{B}$, in the states of monomer, dimer, and complex. Equations $(8,9)$ are valid only if there is no exchange between the monitored nuclei in $\mathrm{A}$ and in $\mathrm{B}$.

To proceed, we define

$$
\begin{aligned}
& \Delta \tilde{\nu}^{\mathrm{A}}=\Delta \nu_{\mathrm{obs}}^{\mathrm{A}}-\left(\frac{[\mathrm{A}]}{[\mathrm{A}]_{\mathrm{o}}} \Delta \nu_{\mathrm{m}}^{\mathrm{A}}+\frac{2\left[\mathrm{~A}_{2}\right]}{[\mathrm{A}]_{\mathrm{o}}} \Delta \nu_{\mathrm{d}}^{\mathrm{A}}\right)=\frac{[\mathrm{AB}]}{[\mathrm{A}]_{\mathrm{o}}} \Delta \nu_{\mathrm{c}}^{\mathrm{A}} \\
& \Delta \tilde{\boldsymbol{v}}^{\mathrm{B}}=\Delta \nu_{\mathrm{obs}}^{\mathrm{B}}-\left(\frac{[\mathrm{B}]}{[\mathrm{B}]_{\mathrm{o}}} \Delta \nu_{\mathrm{m}}^{\mathrm{B}}+\frac{2\left[\mathrm{~B}_{2}\right]}{[\mathrm{B}]_{\mathrm{o}}} \Delta \nu_{\mathrm{d}}^{\mathrm{B}}\right)=\frac{[\mathrm{AB}]}{[\mathrm{B}]_{\mathrm{o}}} \Delta \nu_{\mathrm{c}}^{\mathrm{B}}
\end{aligned}
$$

Clearly, $\Delta \tilde{\nu}^{\mathrm{A}}$ represents the portion of the contribution from the complex $\mathrm{AB}$ to $\Delta v_{\mathrm{obs}}^{\mathrm{A}}$, and $\Delta \tilde{\nu}^{\mathrm{B}}$ that to $\Delta \nu_{\mathrm{obs}}^{\mathrm{B}} . \Delta \tilde{\boldsymbol{v}}^{\mathrm{A}}$ and $\Delta \tilde{\nu}^{\mathrm{B}}$ are calculable if the self- 
association parameters for $\mathrm{A}\left(\Delta \nu_{\mathrm{m}}^{\mathrm{A}}, \Delta \nu_{\mathrm{d}}^{\mathrm{A}}\right.$, and $\left.K_{\mathrm{A}}\right)$, the self-association parameters for B $\left(\Delta \nu_{\mathrm{m}}^{\mathrm{B}}, \Delta \nu_{\mathrm{d}}^{\mathrm{B}}\right.$, and $\left.K_{\mathrm{B}}\right)$, and the hetero-association constant $K_{\mathrm{C}}$ are known.

Substitution of Eq. (6) into Eq. (10) and Eq. (7) into Eq. (11), respectively, followed by rearrangement leads to

$$
\begin{aligned}
& \frac{1}{\Delta \tilde{v}^{\mathrm{A}}}=\frac{1}{\Delta v_{\mathrm{c}}^{\mathrm{A}}}+\left(\frac{1}{[\mathrm{~B}]}+\frac{2 K_{\mathrm{A}}[\mathrm{A}]}{[\mathrm{B}]}\right) \frac{1}{K_{\mathrm{C}} \Delta \nu_{\mathrm{c}}^{\mathrm{A}}} \equiv \frac{1}{\Delta v_{\mathrm{c}}^{\mathrm{A}}}+\frac{\Phi_{\mathrm{A}}}{K_{\mathrm{c}} \Delta \nu_{\mathrm{c}}^{\mathrm{A}}} \\
& \frac{1}{\Delta \tilde{v}^{\mathrm{B}}}=\frac{1}{\Delta v_{\mathrm{c}}^{\mathrm{B}}}+\left(\frac{1}{[\mathrm{~A}]}+\frac{2 K_{\mathrm{B}}[\mathrm{B}]}{[\mathrm{A}]}\right) \frac{1}{K_{\mathrm{C}} \Delta \nu_{\mathrm{c}}^{\mathrm{B}}} \equiv \frac{1}{\Delta v_{\mathrm{c}}^{\mathrm{B}}}+\frac{\Phi_{\mathrm{B}}}{K_{\mathrm{c}} \Delta v_{\mathrm{c}}^{\mathrm{B}}}
\end{aligned}
$$

A plot of $1 / \Delta \tilde{\nu}^{\mathrm{A}} v$ s. $\Phi_{\mathrm{A}}$ permits us to derive $\Delta \nu_{\mathrm{c}}^{\mathrm{A}}$ from the intercept, and $K_{\mathrm{C}}$ from the intercept and the slope. In the same manner $\Delta v_{c}^{\mathrm{B}}$ and $K_{\mathrm{C}}$ can be obtained from a plot of $1 / \Delta \tilde{\nu}^{\mathrm{B}} v s$. $\Phi_{\mathrm{B}}$. Note that regressed values of $K_{\mathrm{C}}$ obtained from Eq. (12) and from Eq. (13) should be equal, since they represent the same hetero-association equilibrium constant. This offers an opportunity for a consistency check of the determination.

In general, the system has nine parameters to be determined: three for self-association parameters of $\mathrm{A}$, their counterparts of $\mathrm{B}$, and another three for hetero-association between A and B. The six self-association parameters can be determined separately by doing experiments on the self-association of A and that of B. Thus, only three parameters $\Delta \nu_{c}^{\mathrm{A}}, \Delta \nu_{\mathrm{c}}^{\mathrm{B}}$ and $K_{\mathrm{C}}$ are left. Now we encounter a dilemma that to determine $K_{\mathrm{C}}$ from the plots based on Eq. (12) [or Eq. (13)] requires $K_{\mathrm{C}}$ to calculate $\Delta \tilde{\nu}^{\mathrm{A}}$ (or $\Delta \tilde{\nu}^{\mathrm{B}}$ ) and $\Phi_{\mathrm{A}}$ and $\Phi_{\mathrm{B}}$. This difficulty can be overcome by the following strategy.

\section{PROPOSED ALGORITHM}

\subsection{Self-Association}

The algorithm for the determination of the monomer shift, dimer shift, and dimerization constant for a self-association has been published elsewhere. ${ }^{(13-15)}$ We will present it only briefly here. For self-association of A, two interconvertible expressions have been derived

$$
\begin{gathered}
\Delta v_{\mathrm{obs}}^{\mathrm{A}}=\Delta v_{\mathrm{d}}^{\mathrm{A}}-\left(\frac{\Delta \nu_{\mathrm{d}}^{\mathrm{A}}-\Delta \nu_{\mathrm{m}}^{\mathrm{A}}}{2 K_{\mathrm{A}}}\right)^{1 / 2}\left(\frac{\Delta \nu_{\mathrm{obs}}^{\mathrm{A}}-\Delta \nu_{\mathrm{m}}^{\mathrm{A}}}{[\mathrm{A}]_{\mathrm{o}}}\right)^{1 / 2} \\
\Delta \nu_{\mathrm{obs}}^{\mathrm{A}}=\Delta \nu_{\mathrm{m}}^{\mathrm{A}}+\left(\Delta \nu_{\mathrm{d}}^{\mathrm{A}}-\Delta \nu_{\mathrm{m}}^{\mathrm{A}}\right) \frac{\left(1+8 K_{\mathrm{A}}[\mathrm{A}]_{0}\right)^{1 / 2}-1}{\left(1+8 K_{\mathrm{A}}[\mathrm{A}]_{0}\right)^{1 / 2}+1}
\end{gathered}
$$

Our method, which combines linear and quadratic regression, is motivated by the following observation: If the value of $\Delta v_{\mathrm{m}}^{\mathrm{A}}$ in $X=\left\{\left(\Delta v_{\mathrm{obs}}^{\mathrm{A}}-\right.\right.$ 
$\left.\left.\Delta \nu_{\mathrm{m}}^{\mathrm{A}}\right) /[\mathrm{A}]_{\mathrm{o}}\right]^{1 / 2}$ is correctly guessed, a linear regression on the data of $\Delta v_{\mathrm{obs}}^{\mathrm{A}}$ vs. $X$ based on Eq. (14) should give a perfect linear fit to the experimental data. The true values of $\Delta v_{\mathrm{d}}^{\mathrm{A}}$ and $K_{\mathrm{A}}$ then can be derived from the intercept and slope of this line. If a quadratic polynomial, in the form of $\Delta v_{\mathrm{obs}}^{\mathrm{A}}=$ $a+b \mathrm{X}+C \mathrm{X}^{2}$, instead of a linear one is tried and the same perfectly-fitted line is returned, the quadratic term of the adjusted equation vanishes and the linear part becomes identical to the former adjusted linear equation. On the other hand, if the value of $\Delta v_{m}^{A}$ is guessed incorrectly, the linear and quadratic regressions will be different. The adjusted linear equation should thus give values of $\Delta v_{\mathrm{d}}^{\mathrm{A}}$ and $K_{\mathrm{A}}$ from the intercept and slope, which are different from the values obtained with the linear part of the adjusted quadratic equation.

The new idea is to plot on the same scale regressed $K_{\mathrm{A}} v s$. guessed $\Delta v_{\mathrm{m}}^{\mathrm{A}}$ for both linear and quadratic regressions. The point representing the true values of $K_{\mathrm{A}}$ and $\Delta \nu_{\mathrm{m}}^{\mathrm{A}}$ will lie upon a curve, $\mathrm{Ll}$, for the linear regression, or, upon Q1 for quadratic regression. We propose that the best values for $K$ and $\Delta v_{\mathrm{m}}^{\mathrm{A}}$ should occur at the intersection, P1, of these two curves.

Now turning to Eq. (15) and following the line of the foregoing argument, we conclude that the regression of $\Delta v_{\mathrm{obs}}^{\mathrm{A}} v s$.

$$
f_{\mathrm{d}}=\frac{\left(1+8 K_{\mathrm{A}}[\mathrm{A}]_{\mathrm{o}}\right)^{1 / 2}-1}{\left(1+8 K_{\mathrm{A}}[\mathrm{A}]_{\mathrm{O}}\right)^{1 / 2}+1}
$$

using linear and quadratic equations will produce from the intercept the same value of $\Delta v_{\mathrm{m}}^{\mathrm{A}}$, if $K_{\mathrm{A}}$ is correctly guessed, or different values otherwise. Plots of guessed values of $K_{\mathrm{A}} v s$. adjusted values of $\Delta v_{\mathrm{m}}^{\mathrm{A}}$, for linear and quadratic regressions, generate curves $\mathrm{L} 2$ and $\mathrm{Q} 2$, respectively. Again, the intersection, $\mathrm{P} 2$, of $\mathrm{L} 2$ and $\mathrm{Q} 2$ should determine the true values of $\Delta \nu_{\mathrm{m}}^{\mathrm{A}}$ and $K_{\mathrm{A}}$.

Ideally, the two intersections $\mathrm{P} 1$ and $\mathrm{P} 2$ should coincide, since they represent the same physical entities. Any departure, however, may reflect:(1) experimental errors in shift and/or solute concentration measurement, (2) extended association beyond dimerization, or (3) nonideal thermodynamic behavior of the solution. The last possibility causes the dimerization constant to depend on the solute concentration. In practical applications, the departure of P1 from P2 should provide a check on consistency as well as a method for estimating errors associated with this graphical determination. To avoid bias associated with choosing either P1 or P2, we should take both into consideration on an equal footing. Accordingly, the average value and standard deviation of $\Delta v_{\mathrm{m}}^{\mathrm{A}}$ (or $K_{\mathrm{A}}$ ) calculated by using P1 and P2 together can be taken as the finally determined value for $\Delta \nu_{\mathrm{m}}^{\mathrm{A}}$ (or $K_{\mathrm{A}}$ ) and its associated error, respectively.

The value of $\Delta v_{\mathrm{m}}^{\mathrm{A}}$ finally determined can then be used to compute $X$, and $\Delta v_{o b s}^{A} v s . X$ can be fitted to Eq. (14) to obtain the true value of $\Delta v_{\mathrm{d}}^{\mathrm{A}}$ from 
the intercept. Similarly, the value of $K_{\mathrm{A}}$ finally determined can also be used to compute $f_{\mathrm{d}}$, and $\Delta v_{\mathrm{obs}}^{\mathrm{A}} v s$. $f_{\mathrm{d}}$ can be fitted to Eq. (15) to obtain the true value of $\Delta v_{\mathrm{d}}^{\mathrm{A}}$ by evaluating $\Delta v_{\mathrm{obs}}^{\mathrm{A}}$ of Eq. (15) at $f_{\mathrm{d}}=1$. The average and standard deviation of $\Delta \nu_{\mathrm{d}}^{\mathrm{A}}$ from the two determinations can then be taken as the final value and error of $\Delta v_{\mathrm{d}}^{\mathrm{A}}$.

\subsection{Hetero-Association}

Equations $(12,13)$ are our central results on which the algorithm for obtaining the complex shifts and hetero-association constant is based. If $K_{\mathrm{A}}$ and $K_{\mathrm{B}}$ have already been determined, with a guessed value of $K_{\mathrm{C}}$, one can solve

$$
\begin{aligned}
& f([\mathrm{~A}])=2 K_{\mathrm{A}}[\mathrm{A}]^{2}+K_{\mathrm{C}}[\mathrm{A}][\mathrm{B}]+[\mathrm{A}]-[\mathrm{A}]_{\mathrm{o}}=0 \\
& g([\mathrm{~A}])=2 K_{\mathrm{B}}[\mathrm{B}]^{2}+K_{\mathrm{C}}[\mathrm{A}][\mathrm{B}]+[\mathrm{B}]-[\mathrm{B}]_{\mathrm{o}}=0
\end{aligned}
$$

at least numerically, for $0<[\mathrm{A}]<[\mathrm{A}]_{\mathrm{o}}$, and $0<[\mathrm{B}]<[\mathrm{B}]_{\mathrm{o}}$ from a pair of initial concentrations of $[A]_{o}$ and $[B]_{0}$. According to Descartes' rule of signs, ${ }^{(17)}$ the number of positive roots of a polynomial equation is equal to the number of variations in signs of the coefficients, If both $[A]$ and $[B]$ are stipulated to be positive, there is only one change in sign for $f([\mathrm{~A}])$ and $g([\mathrm{~A}])$. Hence, each equation has only one positive root. We asserted that $0<[\mathrm{A}]<[\mathrm{A}]_{\mathrm{o}}$, since $f\left([\mathrm{~A}]_{0}\right)=K_{\mathrm{C}}[\mathrm{A}]_{\mathrm{o}}[\mathrm{B}]+2 K_{\mathrm{A}}[\mathrm{A}]_{\mathrm{o}}^{2}>0$, and $f(0)=$ $-[\mathrm{A}]_{\mathrm{o}}<0$. A similar argument leads to $0<[\mathrm{B}]<[\mathrm{B}]_{\text {o }}$.

The solved values of $[\mathrm{A}]$ and $[\mathrm{B}]$ for a guessed value of $K_{\mathrm{C}}$ are then used to calculate $\left[\mathrm{A}_{2}\right]$, and $x=\Phi_{\mathrm{A}}$ in Eq. (12). Also, with the known monomer shift and dimer shift for self-association of $\mathrm{A}$, one can calculate $y=\Delta \tilde{v}^{\mathrm{A}}$. A linear plot of $y$ vs. $x$ based on Eq. (12) gives a regressed value of $K_{\mathrm{C}}$. If $K_{\mathrm{C}}$ is correctly guessed, the regressed value and guessed value will be the same, otherwise they will be different. The correct, finally determined value of $K_{\mathrm{C}}$ may be obtained from the intersection of a plot for $y$ (= regressed values of $K_{\mathrm{C}}$ ) vs. $x$ ( $=$ guessed values of $K_{\mathrm{C}}$ ) and another one for $x=y$. The last plot is just an artifice to locate the point where $K_{\mathrm{C}}$ has the same guessed and regressed values. The regressed value of $\Delta \nu_{c}^{\mathrm{A}}$ obtained from the intercept of the linear plot of $y=\Delta \tilde{\boldsymbol{v}}^{\mathrm{A}} v s . x=\Phi_{\mathrm{A}}$ by using the finally determined value of $K_{\mathrm{C}}$ is then taken as the finally determined value of $\Delta v_{\mathrm{c}}^{\mathrm{A}}$. Now turning to Eq. (13) and following the same procedure to manipulate the data of $\Delta \nu_{\mathrm{obs}}^{\mathrm{B}}$, we will obtain the corresponding results for $K_{\mathrm{C}}$ and $\Delta \nu_{\mathrm{c}}^{\mathrm{B}}$.

\section{EXPERIMENTAL AND RESULTS}

We have carried out NMR experiments at $25^{\circ} \mathrm{C}$ on self-association of 2-pyrrolidone (A), and of 4-methyl- $\alpha$-pyrrolidone (B), and hetero-association 
between them, $\mathrm{A}+\mathrm{B} \rightleftharpoons \mathrm{AB}$, accompanying the foregoing two self-associations, all in acetonitrile- $\mathrm{d}_{3}$. The $300 \mathrm{MHz}$ proton spectra were taken using a Varian Unity-300 NMR spectrometer. All chemicals were highest grade from Aldrich and were used as received. Samples of different concentrations (measured in the units of molality), containing a trace of TMS as a reference, were prepared gravimetrically in small vials with the help of microsyringes. Samples of known concentration were then transferred into $5 \mathrm{~mm} \mathrm{O}$. D. NMR tubes, and were sealed without further degassing.

We monitored the concentration dependence of the shift of the NH peak in $\mathrm{A}$ and/or B. These data were then manipulated and the results plotted by programs written in the Mathematica ${ }^{(18)}$ language and executed on a Digital DECstation 5000/25.

Figure 1 represents a graphic determination of monomer shift and dimerization constant for the self-association of 2-pyrrolidone (A) in acetonitrile$\mathrm{d}_{3}$ at $25^{\circ} \mathrm{C}$ from the dilution shift data listed in Table I. The curves L1 and Q1 represent the plots for regressed values of $K_{\mathrm{A}} v$ s. guessed values of $\Delta v_{\mathrm{m}}^{\mathrm{A}}$, respectively, for linear and quadratic regressions based on Eq. (14).

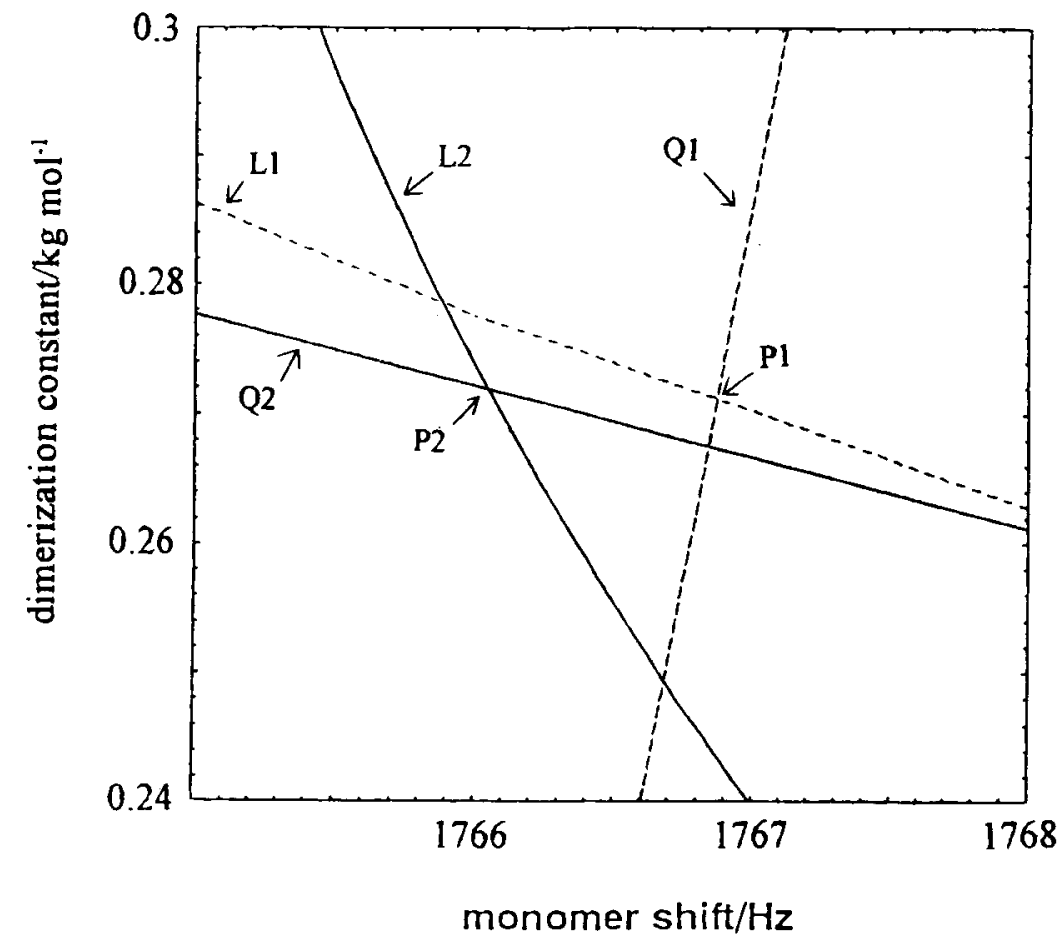

Fig. 1. Graphical determination of monomer shift and dimerization constant for selfassociation of 2-pyrrolidone in acetonitrile- $d_{3}$ at $25^{\circ} \mathrm{C}$ using data listed in Table I. 
Table I. Dilution Shifts of the NH Proton in 2-Pyrrolidone, $\Delta v_{\mathrm{obs}}^{\mathrm{A}}$, at Various Initial Concentrations in Acetonitrile- $\mathrm{d}_{3}$ at $25^{\circ} \mathrm{C}^{a}$

\begin{tabular}{cccc}
\hline$[\mathrm{A}]_{\mathrm{o}}\left(\mathrm{mol}-\mathrm{kg}^{-1}\right)$ & $\Delta v_{\mathrm{obs}}^{\mathrm{A}}(\mathrm{Hz})$ & {$[\mathrm{A}]_{\mathrm{o}}\left(\mathrm{mol}-\mathrm{kg}^{-1}\right)$} & $\Delta v_{\mathrm{obs}}^{\mathrm{A}}(\mathrm{Hz})$ \\
\hline 0.101 & 1804.3 & 1.429 & 2013.6 \\
0.211 & 1832.5 & 1.508 & 2017.1 \\
0.297 & 1852.7 & 1.611 & 2025.9 \\
0.430 & 1886.0 & 1.737 & 2037.9 \\
0.508 & 1902.1 & 1.864 & 2043.5 \\
0.617 & 1916.0 & 1.913 & 2047.7 \\
0.738 & 1935.5 & 2.097 & 2059.6 \\
0.831 & 1951.2 & 2.123 & 2061.1 \\
0.938 & 1965.4 & 2.275 & 2069.0 \\
1.034 & 1975.2 & 2.393 & 2075.3 \\
1.116 & 1983.8 & 2.564 & 2085.2 \\
1.216 & 1991.1 & 2.611 & 2088.5 \\
1.303 & 1999.9 & & \\
\hline
\end{tabular}

${ }^{a}$ Finally determined values: $\Delta v_{\mathrm{m}}^{\mathrm{A}}=1766.2 \pm 0.3 \mathrm{~Hz} ; \Delta \nu_{\mathrm{d}}^{\mathrm{A}}=2492.4 \pm 0.6 \mathrm{~Hz} ; K_{\mathrm{A}}=0.27 \pm 0.01$ $\mathrm{kg}^{\mathrm{mol}} \mathrm{m}^{-1}$.

The curves $\mathrm{L} 2$ and Q2 represent the plots of guessed values of $K_{\mathrm{A}} v s$. regressed values of $\Delta v_{\mathrm{m}}^{\mathrm{A}}$, respectively, for linear and quadratic regressions based on Eq. (15). The intersection $\mathrm{Pl}$ of $\mathrm{L} 1$ and $\mathrm{Q} 1$ then determines the values of $\Delta \nu_{\mathrm{m}}^{\mathrm{A}}$ and $K_{\mathrm{A}}$ based on Eq. (14), while $\mathrm{P} 2$ from L2 and Q2 determines those based on Eq. (15). With P1 and P2, the finally determined values of selfassociation parameters are then read from their midpoint to be $\Delta \nu_{\mathrm{m}}^{\mathrm{A}}=$ $1766.2 \pm 0.3 \mathrm{~Hz}, \Delta v_{\mathrm{d}}^{\mathrm{A}}=2492.4 \pm 0.6 \mathrm{~Hz}, K_{\mathrm{A}}=0.27 \pm 0.01 \mathrm{~kg} / \mathrm{mol}^{-1}$. For the self-association of 4-methyl- $\alpha$-pyrrolidone (B) under the same conditions, the parameters determined by the same procedure are: $\Delta \nu_{\mathrm{m}}^{\mathrm{B}}=3011.7 \pm$ $1.1 \mathrm{~Hz}, \Delta \nu_{\mathrm{d}}^{\mathrm{B}}=4564.7 \pm 1.8 \mathrm{~Hz}, \mathrm{~K}_{\mathrm{B}}=0.98 \pm 0.14 \mathrm{~kg}^{-\mathrm{mol}^{-1}}$, respectively, from the dilution shift data listed in Table II. As shown in Fig. 2, the goodness of determination for self-association of $\mathrm{A}$ is appraised by a comparison of the theoretical curve obtained by putting the determined parameters into Eq. (15) with the experimental points in the plot of $\Delta \nu_{\mathrm{obs}}^{\mathrm{A}} v s$. [A $]_{0}$. A similar plot of $\Delta v_{\mathrm{obs}}^{\mathrm{B}} v s$. [B] $]_{\mathrm{o}}$ for self-association of $\mathrm{B}$ is shown in Fig. 3.

Once $\Delta \nu_{\mathrm{m}}^{\mathrm{A}}, \Delta \nu_{\mathrm{d}}^{\mathrm{A}}, K_{\mathrm{A}}$ for self-association of A, and $\Delta \nu_{\mathrm{m}}^{\mathrm{B}}, \Delta \nu_{\mathrm{d}}^{\mathrm{B}}$, and $K_{\mathrm{B}}$ for self-association of $\mathrm{B}$ have been determined, we are in a position to determine $\Delta \nu_{\mathrm{c}}^{\mathrm{A}}, \Delta v_{\mathrm{c}}^{\mathrm{B}}$, and $K_{\mathrm{C}}$ from the experimental data of $\Delta \nu_{\mathrm{obs}}^{\mathrm{A}}$, and $\Delta \nu_{\mathrm{obs}}^{\mathrm{B}}$ for a pair of initial concentrations $[\mathrm{A}]_{\mathrm{o}}$ and $[\mathrm{B}]_{\mathrm{o}}$ as listed in Table III. With an additional guessed value of $K_{\mathrm{C}}$, and following the procedure stated in Section 3, we are able to make a plot from the data of $\Delta \nu_{\mathrm{obs}}^{\mathrm{A}}$ for various combinations of $[\mathrm{A}]_{\mathrm{O}}$ and $[\mathrm{B}]_{0}$, as shown in Fig. 4, to determine the hetero-association constant as $1.05 \mathrm{~kg}-\mathrm{mol}^{-1}$. Since the $K_{\mathrm{C}}$ determination is solely from the data of 
Table II. Dilution Shifts of the NH Proton in 4-Methyl- $\alpha-$ Pyrrolidone, $\Delta v_{\mathrm{obs}}^{\mathrm{B}}$, at Various Initial Concentrations in Acetonitrile- $\mathrm{d}_{3}$ at $25^{\circ} \mathrm{C}^{a}$

\begin{tabular}{cccc}
\hline$[\mathrm{B}]_{\mathrm{o}}\left(\mathrm{mol}-\mathrm{kg}^{-1}\right)$ & $\Delta \nu_{\mathrm{obs}}^{\mathrm{B}}(\mathrm{Hz})$ & {$[\mathrm{B}]_{\mathrm{o}}\left(\mathrm{mol}-\mathrm{kg}^{-1}\right)$} & $\Delta \nu^{\mathrm{B}}{ }_{\text {obs }(\mathrm{Hz})}$ \\
\hline 0.081 & 3201.9 & 0.239 & 3413.9 \\
0.099 & 3231.9 & 0.264 & 3434.6 \\
0.133 & 3293.7 & 0.282 & 3452.6 \\
0.146 & 3308.0 & 0.308 & 3480.1 \\
0.161 & 3327.8 & 0.320 & 3496.5 \\
0.184 & 3350.2 & 0.334 & 3498.0 \\
0.204 & 3372.8 & 0.363 & 3514.6 \\
0.218 & 3391.9 & & \\
\hline
\end{tabular}

${ }^{a}$ Finally determined values: $\Delta \nu_{\mathrm{m}}^{\mathrm{B}}=3011.7 \pm 1.1 \mathrm{~Hz} ; \Delta \nu_{\mathrm{d}}^{\mathrm{B}}=4564.7 \pm 1.8 \mathrm{~Hz} ; K_{\mathrm{B}}=0.98 \pm 0.14$ kg-mol.

$\Delta \nu_{\text {obs }}^{\mathrm{A}}$, we rename it $K_{\mathrm{C}}^{\mathrm{A}}$. Determination of the hetero-association constant from the data of $\Delta \nu_{\mathrm{obs}}^{\mathrm{B}}$ in Table III is shown in Fig. 5 to have $K_{\mathrm{C}}^{\mathrm{B}}=1.39 \mathrm{~kg}$ $\mathrm{mol}^{-1}$. By using these values just determined and following the procedure outlined in Section 3, $\Delta \nu_{\mathrm{C}}^{\mathrm{A}}=2784.6$, and $\Delta \nu_{\mathrm{c}}^{\mathrm{B}}=3632.5 \mathrm{~Hz}$ are then obtained

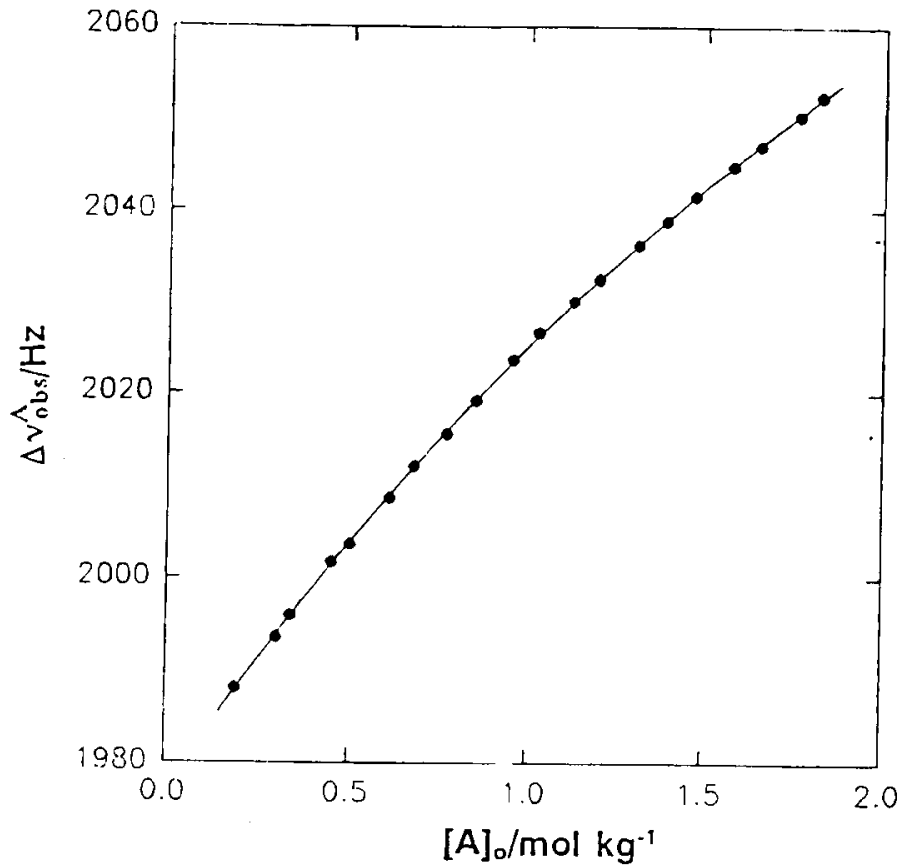

Fig. 2. Plot of observed shift vs. initial concentration for assessment of the determinations of monomer shift, dimer shift, and dimerization constant for self-association of 2-pyrrolidone (A) in acetonitrile- $\mathrm{d}_{3}$ at $25^{\circ} \mathrm{C}$. 


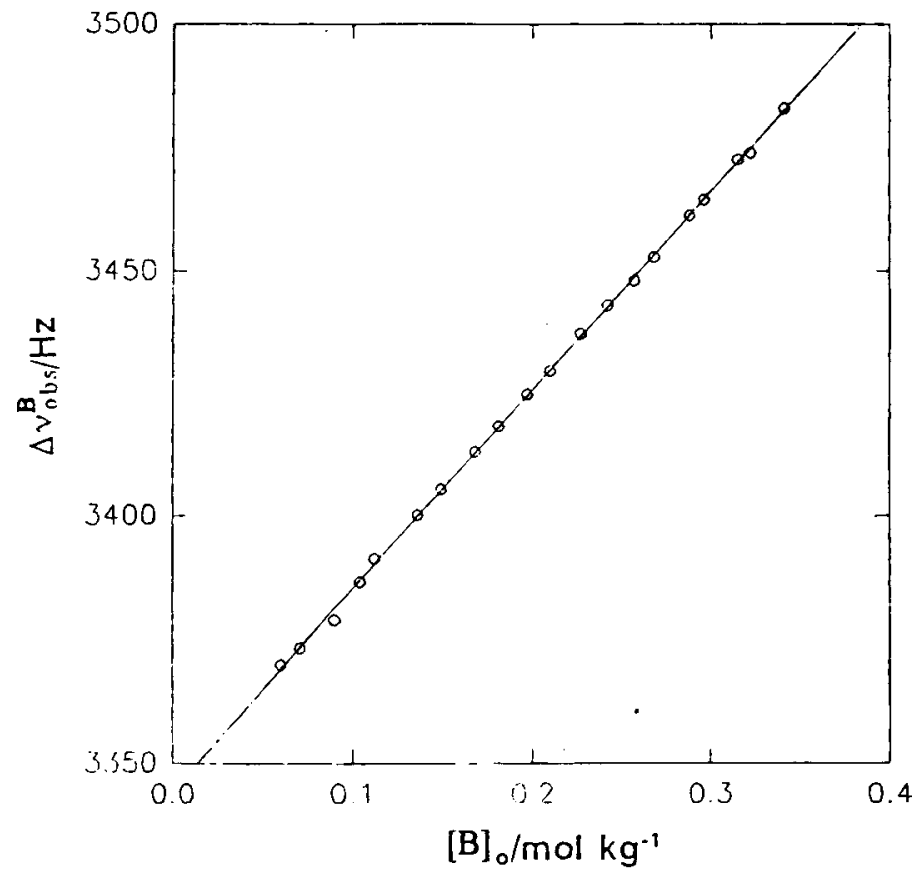

Fig. 3. Plot of observed shift $v$ s. initial concentration for assessment of the determinations of monomer shift, dimer shift, and dimerization constant for self-association of 4-methyl- $\alpha$ pyrrolidone (B) in acetonitrile- $\mathrm{d}_{3}$ at $25^{\circ} \mathrm{C}$.

from the intercepts of the linear plots based on Eqs. $(12,13)$, respectively, as shown in Figs. 6 and 7. We have also collected in Table IV the determined values of monomer, dimer, and complex shifts of $A$ and $B$, the dimerization constants of $A$ and $B$, and the hetero-association constants determine from the $A$ side and from the $B$ side.

The goodness of determination of the six parameters $K_{\mathrm{A}}, K_{\mathrm{B}}, K_{\mathrm{C}}^{\mathrm{A}}$, $\Delta \nu_{\mathrm{m}}^{\mathrm{A}}, \Delta \nu_{\mathrm{d}}^{\mathrm{A}}$, and $\Delta \nu_{\mathrm{c}}^{\mathrm{A}}$ can then be appraised by comparison with the theoretical values (juxtaposed in parentheses) with the observed values, $\Delta v_{\mathrm{obs}}^{\mathrm{A}}$ in Table III. The former are calculated from Eq. (8). A similar comparison is also made for the B side. It appears that the determination of $K_{\mathrm{C}}$ from the A side is better and more reliable.

\section{DISCUSSION}

In the previous publication, ${ }^{(12)}$ dealing with the system of simultaneous equilibria, $\mathrm{A}+\mathrm{A} \rightleftharpoons \mathrm{A}_{2}$, and $\mathrm{A}+\mathrm{B} \rightleftharpoons \mathrm{AB}$, we derived an equation which 
Table III. Chemical Shifts of the NH Proton in 2-Pyrrolidone (A) and in 4-Methyl- $\alpha$ Pyrrolidone (B) for Various Combinations of Initial Concentrations of $[A]_{0}$ and $[B]_{0}$ in Acetonitrile- $d_{3}$ at $25^{\circ} \mathrm{C}^{u}$

\begin{tabular}{cccc}
\hline$[\mathrm{A}]_{\mathrm{o}}\left(\mathrm{mol}-\mathrm{kg}^{-1}\right)$ & {$[\mathrm{B}]_{\mathrm{o}}\left(\mathrm{mol}-\mathrm{kg}^{-1}\right)$} & $\Delta \nu_{\mathrm{obs}}^{\mathrm{A}}(\mathrm{Hz})$ & $\Delta \nu_{\mathrm{obs}}^{\mathrm{B}}(\mathrm{Hz})$ \\
\hline 0.192 & 0.341 & $1988.1(1987.2)^{b}$ & $3482.9(3487.2)^{b}$ \\
0.303 & 0.332 & $1993.6(1992.3)$ & $3473.9(3471.4)$ \\
0.341 & 0.315 & $1995.9(1993.9)$ & $3472.5(3466.4)$ \\
0.452 & 0.296 & $2001.7(1998.9)$ & $3464.4(3454.4)$ \\
0.502 & 0.288 & $2003.7(2001.4)$ & $3461.3(3450.1)$ \\
0.612 & 0.268 & $2008.7(2005.9)$ & $3452.9(3440.7)$ \\
0.679 & 0.257 & $2012.1(2008.9)$ & $3448.1(3436.5)$ \\
0.770 & 0.242 & $2015.6(2013.0)$ & $3443.1(3431.6)$ \\
0.852 & 0.227 & $2019.2(2016.2)$ & $3437.4(3427.1)$ \\
0.955 & 0.210 & $2023.6(2020.7)$ & $3429.8(3423.3)$ \\
1.028 & 0.197 & $2026.6(2023.5)$ & $3425.0(3420.7)$ \\
1.126 & 0.181 & $2030.0(2027.6)$ & $3418.5(3418.3)$ \\
1.197 & 0.168 & $2032.4(2030.1)$ & $3413.2(3416.3)$ \\
1.308 & 0.149 & $2036.2(2034.4)$ & $3405.5(3414.2)$ \\
1.388 & 0.136 & $2038.9(2037.5)$ & $3400.3(3413.3)$ \\
1.471 & 0.112 & $2041.6(2038.6)$ & $3391.2(3408.8)$ \\
1.575 & 0.104 & $2044.9(2044.2)$ & $3386.6(3411.3)$ \\
1.652 & 0.090 & $2047.1(2046.7)$ & $3378.8(3410.5)$ \\
1.762 & 0.071 & $2050.3(2050.5)$ & $3373.2(3410.0)$ \\
1.826 & 0.060 & $2052.5(2052.6)$ & $3369.9(3409.8)$ \\
\hline
\end{tabular}

${ }^{a}$ Finally determined values: $\Delta v_{\mathrm{c}}^{\mathrm{A}}=2784.6 \mathrm{~Hz} ; \Delta \nu_{\mathrm{c}}^{\mathrm{B}}=3632.6 \mathrm{~Hz} ; K_{\mathrm{C}}^{\mathrm{A}}=1.05 \mathrm{~kg}-\mathrm{mol}^{-1}$; $K_{\mathrm{C}}^{\mathrm{B}}=1.39 \mathrm{~kg}-\mathrm{mol}^{-1}$.

${ }^{b}$ Theoretical calculated values in parentheses.

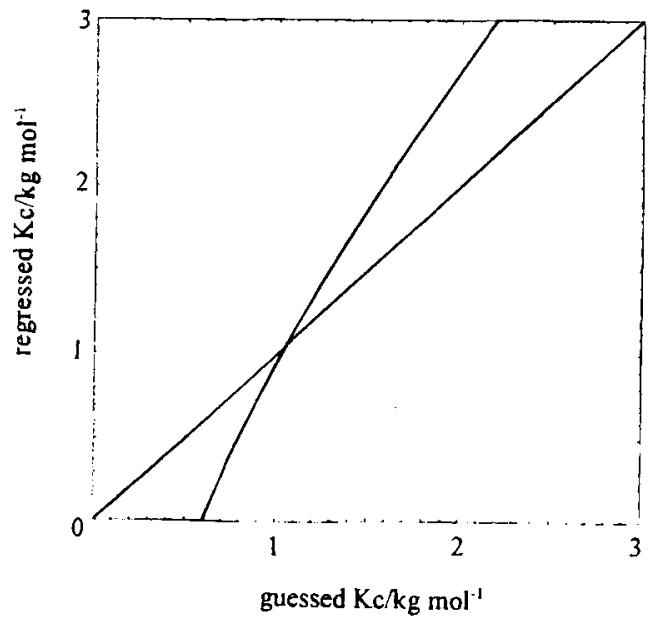

Fig. 4. Graphical determination of $K_{C}^{A}$ based on Eq. (12) from data of $\Delta v_{\mathrm{obs}}^{A}$ for various combination of the initial concentrations of $[A]_{0}$ and $[B]_{0}$ listed in Table III. 


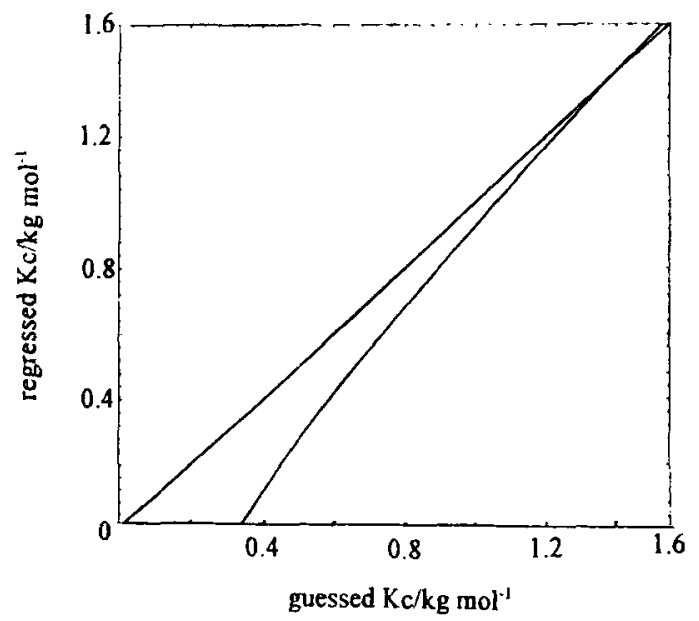

Fig. 5. Graphical determination of $K_{\mathrm{C}}^{\mathrm{B}}$ based on Eq. (13) from the data of $\Delta v_{\mathrm{obs}}^{\mathrm{B}}$ for various combinations of initial concentrations of $[A]_{0}$ and $[B]_{0}$ listed in Table III.

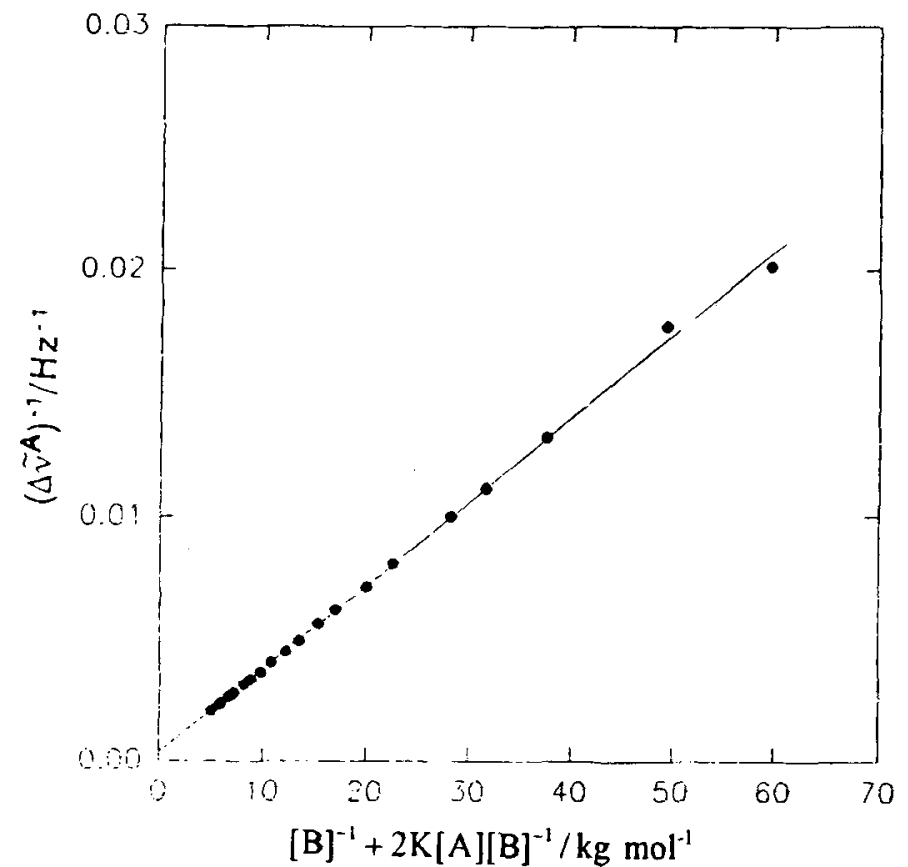

Fig. 6. Linear plot of $\Delta \tilde{\nu}^{A} v s$. $\Phi_{\mathrm{A}}$ based on Eq. (12) using the determined $K_{\mathrm{C}}^{\mathrm{A}}=1.05 \mathrm{~kg}-\mathrm{mol}^{-1}$ to determine $\Delta \nu_{\mathrm{c}}^{\mathrm{A}}$. 


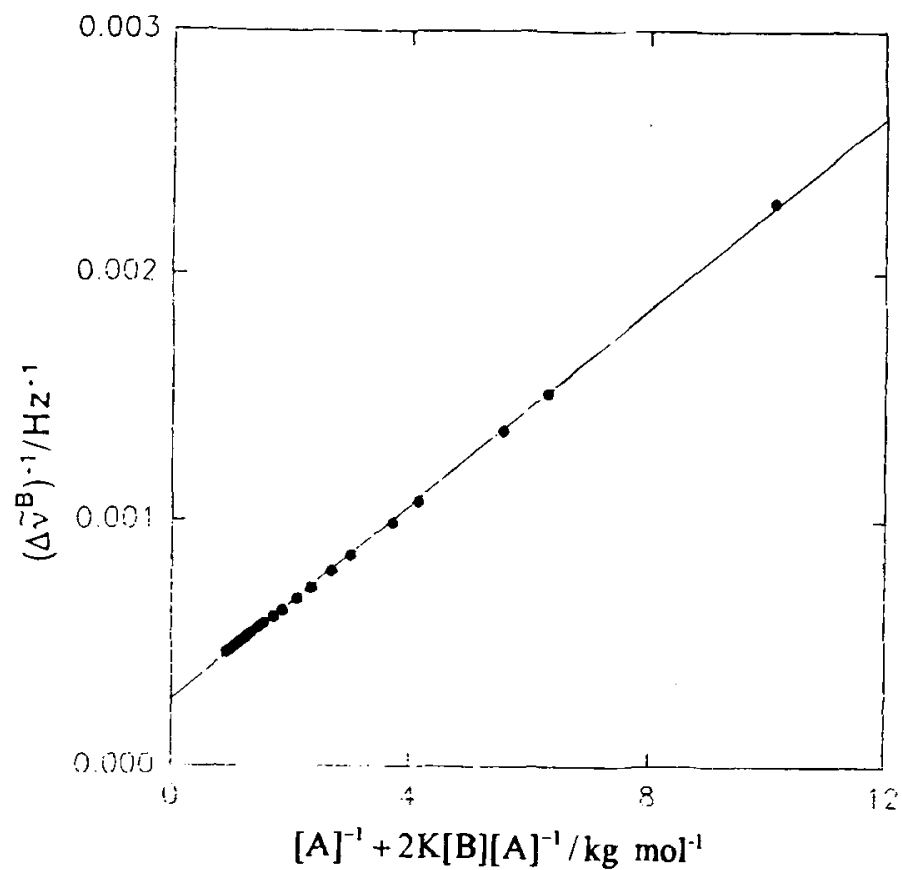

Fig. 7. Linear plot of $\Delta \tilde{v}^{\mathrm{B}} v s$. $\Phi_{\mathrm{B}}$ based on Eq. (13) using the determined $K_{\mathrm{C}}^{\mathrm{B}}=$ $1.39 \mathrm{~kg}-\mathrm{mol}^{-1}$ to determine $\Delta v_{\mathrm{c}}^{\mathrm{B}}$.

governs the chemical shifts as a function of concentrations of $A$ and $B$

$$
\frac{[\mathrm{B}]_{\mathrm{o}}}{\Delta \tilde{\boldsymbol{v}}^{\mathrm{A}}[\mathrm{A}]_{\mathrm{o}}}=\frac{1}{\Delta \nu_{\mathrm{c}}^{\mathrm{A}}}+\frac{1}{K_{\mathrm{C}} \Delta \nu_{\mathrm{c}}^{\mathrm{A}}} \frac{1}{[\mathrm{~A}]}
$$

where $\Delta \tilde{\nu}^{\mathrm{A}}$ is defined as in Eq. (10). This system is a special case of our general system excluding the self-association of $\mathrm{B}$. Therefore, it is expected

Table IV. Collected Data of the Final Determination of Monomer,

Dimer, and Complex Shifts and the Self- and Hetero-Association

Constants

\begin{tabular}{ll}
\hline & Self-association \\
$\mathrm{A}+\mathrm{A} \rightleftharpoons \mathrm{A} 2$ & $\mathrm{~B}+\mathrm{B} \rightleftharpoons \mathrm{B} 2$ \\
$\delta_{\mathrm{m}}^{\mathrm{A}}=1766.2 \pm 0.3 \mathrm{~Hz}$ & $\delta_{\mathrm{m}}^{\mathrm{B}}=3011.7 \pm 1.1 \mathrm{~Hz}$ \\
$\delta_{\mathrm{d}}^{\mathrm{A}}=2492.4 \pm 0.6 \mathrm{~Hz}$ & $\delta_{\mathrm{d}}^{\mathrm{B}}=4564.7 \pm 1.8 \mathrm{~Hz}$ \\
$K_{\mathrm{d}}^{\mathrm{A}}=0.27 \pm 0.01 \mathrm{~kg}-\mathrm{mol}^{-1}$ & $K_{\mathrm{d}}^{\mathrm{B}}=0.98 \pm 0.14 \mathrm{~kg}-\mathrm{mol}^{-1}$ \\
\multicolumn{1}{c}{ Hetero-association $\mathrm{A}+\mathrm{B} \rightleftharpoons \mathrm{AB}^{\text {From signal of A }}$} & From signal of B \\
$\Delta \nu_{\mathrm{c}}^{\mathrm{A}}=2784.6 \mathrm{~Hz}$ & $\Delta \nu_{\mathrm{c}}^{\mathrm{B}}=3632.6 \mathrm{~Hz}$ \\
$K_{\mathrm{C}}^{\mathrm{A}}=1.05 \mathrm{~kg}-\mathrm{mol}^{-1}$ & $K_{\mathrm{C}}^{\mathrm{B}}=1.39 \mathrm{~kg}^{-1} \mathrm{~mol}^{-1}$ \\
\hline
\end{tabular}


that Eq. (12) can be reduced to Eq. (18) with $K_{\mathrm{B}}=0$. In order to prove this, Eq. (12) is rewritten

$$
\frac{1}{\Delta \tilde{\nu}^{\mathrm{A}}}=\frac{1}{\Delta \nu_{\mathrm{c}}^{\mathrm{A}}}+\left(1+2 K_{\mathrm{A}}[\mathrm{A}]+K_{\mathrm{C}}[\mathrm{B}]-K_{\mathrm{C}}[\mathrm{B}]\right) \frac{1}{[\mathrm{~B}]} \frac{1}{K_{\mathrm{C}} \Delta \nu_{\mathrm{c}}^{\mathrm{A}}}
$$

With Eq. (4) this becomes

$$
\begin{aligned}
\frac{1}{\Delta \tilde{\nu}^{\mathrm{A}}} & =\frac{1}{\Delta \nu_{c}^{\mathrm{A}}}+\left(\frac{[\mathrm{A}]_{\mathrm{o}}}{[\mathrm{A}]}-K_{\mathrm{C}}[\mathrm{B}]\right) \frac{1}{[\mathrm{~B}]} \frac{1}{K_{\mathrm{C}} \Delta \nu_{\mathrm{c}}^{\mathrm{A}}} \\
& =\frac{[\mathrm{A}]_{\mathrm{o}}}{[\mathrm{A}]} \frac{1}{[\mathrm{~B}]} \frac{1}{K_{\mathrm{c}} \Delta \nu_{\mathrm{c}}^{\mathrm{A}}}
\end{aligned}
$$

If Eq. (5) is used with $K_{\mathrm{B}}=0$, i.e., $\left[\mathrm{B}_{2}\right]=0$, then $1 /[\mathrm{B}]=\left(1+K_{\mathrm{c}}[\mathrm{A}]\right) /$ $[B]_{0}$. Substituting this into Eq. (20), restores Eq. (18).

Moreover, it is also expected that, if the monitored nucleus is in B, Eq. (13), or its alternative Eq. (11), can be reduced to the B-H equation if without any self-association, and $[A]_{0}>>[B]_{0}$. In such a case, $\left[B_{2}\right]=0$, and Eq. (11) is then reduced to

$$
\Delta \tilde{\nu}^{\mathrm{B}}=\Delta \nu_{\mathrm{obs}}^{\mathrm{B}}-\frac{[\mathrm{B}]}{[\mathrm{B}]_{\mathrm{o}}} \Delta \nu_{\mathrm{m}}^{\mathrm{B}}=\frac{[\mathrm{AB}]}{[\mathrm{B}]_{\mathrm{o}}} \Delta \nu_{\mathrm{c}}^{\mathrm{B}}
$$

subtracting $\left([\mathrm{AB}] /[\mathrm{A}]_{0}\right) \Delta \nu_{\mathrm{m}}^{\mathrm{A}}$ from both sides of the last equality, Eq. (21) becomes

$$
\Delta \nu_{\mathrm{obs}}^{\mathrm{B}}-\Delta \nu_{\mathrm{m}}^{\mathrm{B}}=\frac{[\mathrm{AB}]}{[\mathrm{B}]_{\mathrm{o}}}\left(\Delta \nu_{\mathrm{c}}^{\mathrm{B}}-\Delta \nu_{\mathrm{m}}^{\mathrm{B}}\right)
$$

which can be rearranged to be in the form of the $\mathrm{B}-\mathrm{H}$ equation

$$
\frac{1}{\Delta \nu_{\mathrm{obs}}^{\mathrm{B}}-\Delta \nu_{\mathrm{m}}^{\mathrm{B}}}=\frac{1}{\Delta \nu_{\mathrm{c}}^{\mathrm{B}}-\Delta \nu_{\mathrm{m}}^{\mathrm{B}}}+\frac{1}{\left(\Delta \nu_{\mathrm{c}}^{\mathrm{B}}-\Delta \nu_{\mathrm{m}}^{\mathrm{B}}\right) K_{\mathrm{C}}} \frac{1}{[\mathrm{~A}]_{\mathrm{o}}}
$$

after the use of Eq. (7) and the approximation of $[\mathrm{A}] \cong[\mathrm{A}]_{\mathrm{o}}$ have been made. The approximation is justified by the conditions $K_{\mathrm{A}}=0$, and $[\mathrm{A}]_{\mathrm{o}}>>[\mathrm{B}]_{\mathrm{o}}$.

In order to appreciate the superiority of our method over B-H method, we also treated the data using $\mathrm{B}-\mathrm{H}$ method pretending that equilibria (2) and (3) do not occur. To fulfil the requirements of the B-H method, we only sort from the data of $\Delta v_{\mathrm{obs}}^{\mathrm{B}} v s$. [A $]_{\mathrm{o}}$ the portion with $[\mathrm{A}]_{\mathrm{o}} \geq 1.388 \mathrm{~mol}-\mathrm{kg}^{-1}$, where $[\mathrm{B}]_{\mathrm{o}} /[\mathrm{A}]_{\mathrm{o}}<0.1$. The result of such a B-H plot based on Eq. (23) with $\Delta \nu_{\mathrm{m}}^{\mathrm{B}}=3011.7 \mathrm{~Hz}$ is presented in Fig. 8, where a fairly good fitt to a straight line is found. From the plot we obtain a negative value of the heteroassociation constant. Thus, ignoring the self-association of the components 


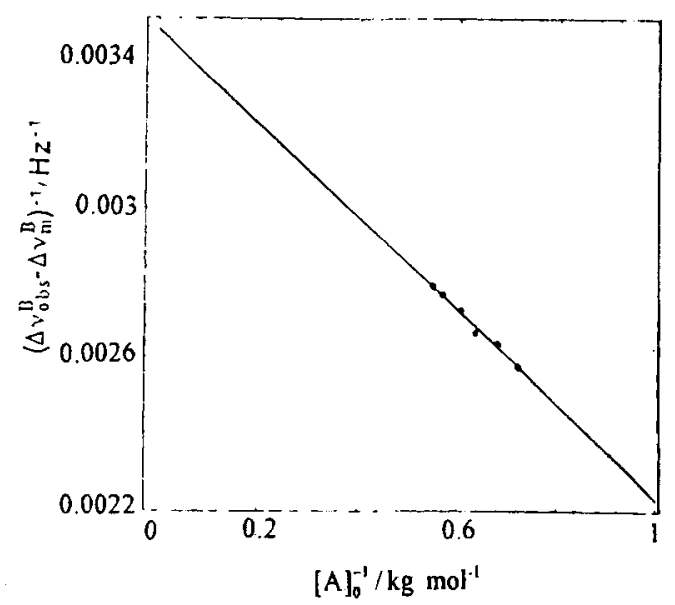

Fig. 8. B-H plot using $\Delta \nu_{\mathrm{m}}^{\mathrm{B}}=3011.7 \mathrm{~Hz}$ for the determination of $\Delta \nu_{\mathrm{c}}^{\mathrm{B}}$ and $K_{\mathrm{C}}$ from the portion of the data of $\Delta v_{\mathrm{obs}}^{\mathrm{B}} v \mathrm{~s}$. [A] $]_{\mathrm{o}}$ with $[\mathrm{A}]_{\mathrm{o}} \geq 1.388 \mathrm{~mol}-\mathrm{kg}^{-1}$ in Table III. Note that the heteroassociation constant is negative from this determination.

in a system where the hetero-association coexisting with self-association in using the B-H plot may lead to an absurd determination of the heteroassociation constant.

\section{CONCLUSION}

In conjunction with the graphical method for the determination of monomer shift, dimer shift, and dimerization constant from the dilution shift data of a self-association system, we have proposed a new algorithm which enables us to determine the values of complex shift and equilibrium constant for a hetero-association $\mathrm{A}+\mathrm{B} \rightleftharpoons \mathrm{AB}$, accompanying self-associations $\mathrm{A}+\mathrm{A} \rightleftharpoons$ $\mathrm{A}_{2}, \mathrm{~B}+\mathrm{B} \rightleftharpoons \mathrm{B}_{2}$. Our method is superior to the conventional $\mathrm{B}-\mathrm{H}$ method because the limitation of the assumption that the concentration of one constituent must be much less than that of the other is removed, and the possibility of self-associations of $A$ and $B$ is taken into account. With a practical example of the coexisting self-association and hetero-association of 2-pyrrolidone (A) and that of 4-methyl- $\alpha$-pyrrolidone (B) in acetonitrile- $\mathrm{d}_{3}$ at $25^{\circ} \mathrm{C}$, we have Jemonstrated that the new algorithm gives better results than the $\mathrm{B}-\mathrm{H}$ method. We believe that our new algorithm will lend itself to reliable thermodynamic itudies of association systems by NMR or other spectroscopic means.

\section{ACKNOWLEDGMENT}

JSC wishes to express his gratitude for the support of this project from he National Science Council of Taiwan under grant number NSC 86-2113 M009-008. 


\section{REFERENCES}

1. J. Rose, Molecular Complexes, (Pergamon Press, Oxford, 1967).

2. R. Foster, ed. Molecular Association, Vols. 1 and 2, (Academic Press, London, 1975).

3. P. Hobza and R. Zahradnik, Weak Intermolecular Interactions in Chemistry and Biology, Studies in Physical and Theoretical Chemistry 3, (Elsevier, Amsterdam, 1978).

4. P. Hobza and R. Zahradnik, Intermolecular Complexes, Studies in Physical and Theoretical Chemistry 52, (Elsevier, Amsterdam, 1988).

5. E. Wyn-Jones and J. Gormally, eds. Aggregation Processes in Solutions, Studies in Physical and Theoretical Chemistry 26, (Elsevier, Amsterdam, 1983).

6. J. C. Dore and J. Teixeira, eds. Hydrogen-Bonded Liquids, (Kluwer Academic Publishers, Dordrecht, 1989).

7. J. S. Davies, Jr. and K. K. Deb, Advn. Magn. Reson. 4, 201 (1970).

8. A. H. Benesi and J. H. Hildebrand, J. Amer. Chem. Soc. 70, 2832(1948); 71, 2703 (1949).

9. G. Scatchard, Ann. N. Y. Acad. Sci. 51, 660(1949).

10. R. L. Scott, Rec. Trav. Chim. 75, 787 (1956).

11. A. Streitweisser, C. H. Heathcock, and E. M. Kosower, Introduction to Organic Chemistry, 4th edn., (Macmillan, New York, 1992) Chap 23.

12. J. S. Chen and J. C. Shiao, J. Chem. Soc. Faraday Trans. 90,429 (1994).

13. J. S. Chen and R. B. Shirts, J. Phys. Chem. 89, 1643 (1985).

14. J. S. Chen and F. Rosenberger, Tetrahedron Letters, 31, 3975 (1990).

15. J. S. Chen, J. Chem. Soc. Faraday Trans. 90, 717 (1994).

16. H. S. Gutowsky and A. Saika, J. Chem. Phys. 21, 1688 (1953).

17. C. C. MacDuffee, Theory of Equations, (Wiley, New York, 1954).

18. S. Wolfram, Mathematica, A System for Doing Mathematics by Computer, 2nd edn., (Addison-Wesley, Redwood City, CA, 1991). 